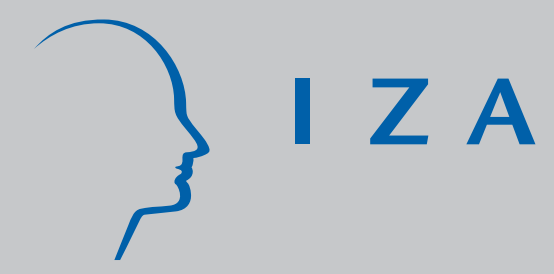

IZA DP No. 814

Measuring Labor Market Frictions:

A Cross-Country Comparison

Geert Ridder

Gerard J . van den Berg

July 2003 


\title{
Measuring Labor Market Frictions: A Cross-Country Comparison
}

\author{
Geert Ridder \\ University of Southern California \\ Gerard J. van den Berg \\ Free University of Amsterdam, Tinbergen Institute, IFAU-Uppsala, \\ INSEE-CREST, CEPR and IZA Bonn
}

\author{
Discussion Paper No. 814 \\ July 2003
}

\author{
IZA \\ P.O. Box 7240 \\ D-53072 Bonn \\ Germany \\ Tel.: +49-228-3894-0 \\ Fax: +49-228-3894-210 \\ Email: iza@iza.org
}

This Discussion Paper is issued within the framework of IZA's research area Evaluation of Labor Market Policies and Projects. Any opinions expressed here are those of the author(s) and not those of the institute. Research disseminated by IZA may include views on policy, but the institute itself takes no institutional policy positions.

The Institute for the Study of Labor (IZA) in Bonn is a local and virtual international research center and a place of communication between science, politics and business. IZA is an independent, nonprofit limited liability company (Gesellschaft mit beschränkter Haftung) supported by Deutsche Post World Net. The center is associated with the University of Bonn and offers a stimulating research environment through its research networks, research support, and visitors and doctoral programs. IZA engages in (i) original and internationally competitive research in all fields of labor economics, (ii) development of policy concepts, and (iii) dissemination of research results and concepts to the interested public. The current research program deals with (1) mobility and flexibility of labor, (2) internationalization of labor markets, (3) welfare state and labor market, (4) labor markets in transition countries, (5) the future of labor, (6) evaluation of labor market policies and projects and (7) general labor economics.

IZA Discussion Papers often represent preliminary work and are circulated to encourage discussion. Citation of such a paper should account for its provisional character. A revised version may be available on the IZA website (www.iza.org) or directly from the author. 
IZA Discussion Paper No. 814

July 2003

\section{ABSTRACT \\ Measuring Labor Market Frictions: A Cross-Country Comparison*}

In this paper we define and estimate measures of labor market frictions using data on job durations. We compare different estimation methods and different types of data. We propose and apply an unconditional inference method that can be applied to aggregate duration data. It does not require wage data, it is invariant to the way in which wages are determined, and it allows workers to care about other job characteristics. The empirical analysis focuses on France, but we perform separate analyses for the USA, the UK, Germany and the Netherlands. We quantify the monopsony power due to search frictions and we examine the policy effects of the minimum wage, unemployment benefits and search frictions.

JEL Classification: J6, J3, C4, C5

Keywords: $\quad$ wages, search frictions, cross-country comparisons, monopsony power, minimum wage, job search, mobility, labor market policy

Corresponding author:

Gerard J. van den Berg

Department of Economics

Free University of Amsterdam

De Boelelaan 1105

1081 HV Amsterdam

The Netherlands

Email: gjvdberg@xs4all.nl

\footnotetext{
* An earlier version of this paper had the title "Estimating Measures of Labor Market Imperfection for Five OECD Countries, Using Aggregate Data in an Equilibrium Search Framework". We thank the Editor and anonymous Referees for their comments, and Niels de Visser for his excellent research assistance. Useful comments were also provided by seminar participants at NYU, UPenn, Penn State, UCL, Johns Hopkins, Tilburg, Queen's, IZA Bonn, Uppsala, and Groningen, and by participants at ESEM, SOLE, CILN, and Cowles Commission conferences, in particular by Zvi Eckstein, Ken Wolpin, Manuel Arellano, John Kennan, and Annette Bergemann.
} 


\section{Introduction}

During the past decades, a literature has emerged that emphasizes the importance of labor market frictions and the resulting labor market flows for the understanding of labor market outcomes like wages and unemployment (see Mortensen and Pissarides, 1999, for a survey). In this paper we aim to quantify the amount of search frictions in the labor market. We define an index of search frictions as the average number of job offers that a worker receives during a spell of employment (that is, during a time period between two unemployment spells). The larger this number, the smaller the degree of frictions. This number is relevant

for wage determination: if it is large then it is relatively easy for workers to leave a firm for another firm, so it reflects the power of workers vis-à-vis employers.

We develop and apply a number of ways to estimate the index of search frictions. These are distinguished by data availability and the extent to which theoretical restrictions are imposed on the model. In all cases we postulate that direct job-to-job transitions are driven by the desire to improve one's position on the labor market, so that the new job has a higher value than the old job. The simplest case is the standard partial on-the-job search model where workers are only interested in the wage of a job (see e.g. Mortensen, 1986). In that case, a sample from the joint distribution of wages and job durations at the individual level basically suffices to estimate the index of search frictions. Such data are 
typically provided by longitudinal micro surveys. We demonstrate that, as an alternative approach, one may discard wage observations and estimate the index from data on job durations only. Estimation can be carried out with micro data but also with various types of aggregate data on job durations. This alternative approach does not impose that workers are only interested in wage improvement but also allows them to care about other job characteristics. The estimated index is robust with respect to what drives wage dispersion at the individual level and with respect to which job characteristics determine the job value. It does not require estimation of a wage (offer) distribution and it is also robust with respect to the level of an institutional wage floor like a minimum wage.

In the paper we estimate the index in a number of different ways with micro as well as aggregate data from France and from other countries. The results clarify the usefulness of the various approaches. Approaches based on aggregate data are potentially useful when micro panel data are not available or suffer from small numbers of observations or high attrition rates.

It is well known that the presence of search frictions gives employers a certain amount of monopsony power. Basically, if the worker's valuation of the job is strictly smaller than the value of the marginal product of the workers, then the firm may still maintain a positive workforce, because it takes time for the worker to find a better job. The extent to which employers can exploit this depends on the speed at which workers can move to other jobs. We use the estimated index of search frictions to quantify the average monopsony power, defined as the average fraction of the revenue product that is not given to the worker. This is not possible without additional data and assumptions, for the reason that it requires a quantification of the difference between the match value and the share given to the worker. Here we assume that jobs are fully characterized by wages, and that wages are determined according to the equilibrium search model of Van den Berg and Ridder (1998), which extends the model of Burdett and Mortensen (1998) (see Van den Berg, 1999, and Mortensen and Pissarides, 1999, for surveys of equilibrium search models). Basically, the estimated index of search frictions and data on the mean wage are used to back out the mean revenue product. 
With this in hand, it is possible to perform policy analyses, by computing counterfactual measures of the degree of monopsony power. We focus on the mandatory minimum wage, or, more generally, the institutional wage floor. A minimum wage decreases the amount of monopsony power. We contrast the effect of changes in the minimum wage to the effect of changes in the amount of frictions in the labor market. It turns out that a minimum wage, although being a simple and transparent policy measure, is inferior as a means to reduce monopsony power, compared to measures that reduce frictions and stimulate mobility.

The outline of the paper is as follows. Section 2 deals with methods of inference on labor market frictions. Section 3 presents the empirical analyses for France. In Subsection 4.1 we apply our methods to aggregate data from a few other European countries, whereas in Subsection 4.2 we discuss difficulties with application to the U.S. labor market. Section 5 concerns the policy analyses. Section 6 concludes.

\section{Inference on the amount of labor market frictions}

\subsection{A simple model of job-to-job transitions}

We start by briefly presenting the standard partial on-the-job search model with repeated search. Suppose that workers only care about the value of an index of job characteristics $w$. In this subsection we call $w$ the wage of the job. Workers obtain job offers, which are random drawings from the wage offer distribution $F(w)$, at an exogenous rate $\lambda$. Whenever an offer arrives, the decision has to be made whether to accept it or to reject it and search further for a better offer. Layoffs accrue at the constant exogenous rate $\delta$. Employed workers then accept any wage offer that exceeds their current wage. Concerning unemployed workers we assume that their optimal job acceptance strategy is characterized by a reservation wage $r$.

The quantity $k:=\lambda / \delta$ equals the average number of job offers in a given spell of employment. To see this, condition first on the length of the employment spell and compute the expected number of offers. The Poisson distribution with intensity rate $\lambda$ over a time period with length $h$ has expectation $\lambda h$. So over a given length $d$ of the employment 
spell, the expected number of offers equals $\lambda d$. Then the unconditional expectation of the number of offers equals $\lambda \mathrm{E}(d)=\lambda / \delta$. We take the latter as our index of search frictions. It equals the rate at which job opportunities arise as a fraction of the rate at which they are needed. The quantity $k$ plays a major role in the equilibrium specification of the wage offer distribution in equilibrium search models (see the surveys mentioned in Section 1). ${ }^{1}$ A low value of $\delta$ may be a result of stringent job protection laws, and thus may reflect an important source of labor market frictions. For this reason, we do not focus exclusively on $\lambda / \delta$ as the index of search frictions, but we also examine the value of $\lambda$.

In this model, firms do not offer a wage below $r$, because they would not attract any workers. This implies that all offers are acceptable to the unemployed. The lowest wage offer $\underline{w}$ will not be strictly larger than $\max \left\{r, w_{\min }\right\}$ either (where $w_{\text {min }}$ is the mandatory or legal minimum wage), because otherwise the profit flow could be increased by reducing this lowest offer.

Let the distribution of wages paid to a cross-section of employees have distribution function $G$. To distinguish $G$ from $F$ we call $G$ the cdf of earnings. Earnings are on average higher than wage offers because workers stay on average longer in higher paying jobs. In the steady state, flows into and out of the stock of employees with a wage less or equal to $w$ are equal. We show that this implies that

$$
G(w)=\frac{F(w)}{1+k(1-F(w))},
$$

We normalize the measure of employed workers to 1 . The flow out of employment has measure $\delta$. In the steady state this equals the flow into employment. The stock of employees with a wage less than or equal to $w$ has measure $G(w)$. The flow into this stock consists of unemployed who accept a wage less than or equal to $w$. This flow is equal to the fraction $F(w)$ of the total flow into employment, so this equals $F(w) \cdot \delta$. The flow out of this stock

\footnotetext{
${ }^{1}$ In empirical studies, the estimated values of $\lambda$ and $k$ are often positively correlated across markets with the estimated value of the job offer arrival rate of unemployed workers (see e.g. Ridder and Van den Berg, 1997). Therefore, $\lambda$ and $k$ may also capture the amount of frictions for the unemployed. Van den Berg and Van Vuuren (2001) argue that $\lambda$ and $k$ depend less strongly on other model determinants than the job offer arrival rate of unemployed workers.
} 
consists of those who leave employment (measure $\delta G(w)$ ) and those who receive a job offer that exceeds $w$ (measure $\lambda(1-F(w)) G(w)$ ). Equation (1) follows. Usually, this relation is derived within an equilibrium search model (see e.g. Burdett and Mortensen, 1998). In such models, $F$ is derived, but for (1) $F$ can be taken as a primitive.

\subsection{Conditional inference}

For expositional reasons we discuss conditional (on $w$ ) inference on the index of search frictions before we discuss unconditional inference. In the present subsection we take $w$ to equal the wage in the job, we assume that workers are only interested in wage income, and we assume we have access to a sample from the joint distribution of elapsed job durations and wages among currently employed workers. Note that this joint distribution can be obtained from cross-sectional data if one is prepared to use retrospective information. In practice such information may be absent or unreliable, and one may want to allow for other job characteristics. This is why in the next subsection we examine unconditional inference.

From the job exit rate $\lambda(1-F(w))+\delta$ of a worker who currently earns $w$, it is clear that the conditional distribution of job durations given $w$ yields a direct estimate of $\lambda$ as the coefficient of $1-F(w)$. This can be performed straightforwardly by maximum likelihood. The difference of the job exit rate at the lowest and at the highest wage is precisely equal to $\lambda$, and the job exit rate at the highest wage equals $\delta$, but it is not attractive to use these relations for estimation because the observation of extreme wages is very sensitive to measurement error. Flinn (2002) estimates the model with maximum likelihood, allowing for measurement errors.

We now discuss an alternative approach that is insensitive to measurement errors and that is very easy to carry out. It exploits the steady state condition (1) for worker flows. From this equation,

$$
\frac{1}{\delta+\lambda(1-F(w))}=\frac{1}{\delta(1+k)}+\frac{k}{\delta(1+k)} G(w)
$$

Hence, the model of repeated search and the steady state conditions imply a linear relation between the average length of a job spell given $w$ and the cdf of earnings at $w$. Note that 
this provides an overidentifying restriction, because the data allow for a nonlinear relation. More importantly, the ratio of the slope coefficient and the intercept is an estimator of $k$. In the next subsection we show that the hazard rate of the distribution of elapsed job durations given $w$ is also equal to $\delta+\lambda(1-F(w))$. So, the left-hand side of (2) is also the average elapsed job duration given $w$. One may therefore estimate $k$ from a regression of the average elapsed duration of employed workers with a wage $w$ on the fraction of the employed workers who have a wage of $w$ or less. One may also estimate $k$ from the equality of the reciprocal of the left-hand side of the above equation and the reciprocal of the right-hand side (this expresses the hazard rate given $w$ as a function of $G(w)$ ). Note that $G$ is directly estimable, either by the empirical cdf of wages or by a parametric cdf.

As noted, conditional inference requires one to assume that the wage is the only job characteristic that matters for the individual's behavior. Gronberg and Reed (1994) and Hwang, Mortensen and Reed (1998) examine equilibrium search models where firms set wages as well as values of non-wage job characteristics. In equilibrium, firms with a high innate labor productivity offer higher wages as well as better values of the non-wage characteristics. This suggests that the wage may proxy the over-all value of the job.

\subsection{Unconditional inference}

Readily available data from the OECD and similar sources (see Sections 3 and 4) contain information on a number of quantities that are related to job durations and flows into and out of jobs. These quantities are unconditional on job characteristics like the wage in the job. To derive their counterparts in the model we have to integrate $w$ out of the conditional job duration distribution. If $k$ is identified from these quantities then, contrary to the previous subsection, the inference is robust with respect to which job characteristics drive the job-to-job transitions. A similar approach can be applied to micro data in which the information on wages is discarded.

To proceed, we need to distinguish between three different unconditional distributions

of job spells. They are defined for three different populations: (i) the population of workers who move from unemployment to employment at a given point in time, the E-inflow 
population, (ii) the population of workers who start in a job at a given point in time, the J-inflow population, and (iii) the population of workers who are employed at a given point in time, the E-stock. The J-inflow differs from the E-inflow because the former contains workers who make a direct job-to-job transition, and these will accept on average higher $w$ than the workers who flow in from unemployment. If we integrate out $w$, we introduce unobserved heterogeneity in an exponential duration distribution. As a consequence, the duration density in the stock differs from that in the inflow (see e.g. Ridder, 1984).

For the inflow populations the conditional distribution of job durations $t$ given $w$ has density

$$
\varphi(t \mid w)=(\delta+\lambda \bar{F}(w)) e^{-(\delta+\lambda \bar{F}(w)) t}
$$

with $\bar{F}:=1-F$. The only difference between the E-inflow and the J-inflow concerns the distribution of $w$, which has density $f(w)$ in the E-inflow, and density

$$
\varphi(w)=\frac{k}{\log (1+k)} \frac{f(w)}{1+k \bar{F}(w)}
$$

in the J-inflow (see our working paper version Ridder and Van den Berg, 2002, for a derivation). We obtain

Proposition 1 (i) The density of the job duration $t_{u j}$ in the E-inflow is

$$
\varphi\left(t_{u j}\right)=\frac{e^{-\delta t_{u j}}}{\delta k t_{u j}^{2}}\left[1+\delta t_{u j}-\left(1+\delta(1+k) t_{u j}\right) e^{-\delta k t_{u j}}\right]=\frac{1}{\lambda} \int_{\delta}^{\delta+\lambda} z e^{-z t_{u j}} d z
$$

(ii) The density of the job duration $t_{* j}$ in the J-inflow is

$$
\varphi\left(t_{* j}\right)=\frac{1}{\log (1+k)} \frac{1}{t_{* j}} e^{-\delta t_{* j}}\left[1-e^{-\lambda t_{* j}}\right]=\frac{1}{\log (1+k)} \int_{\delta}^{\delta+\lambda} \frac{1}{z}\left[z e^{-z t_{* j}}\right] d z
$$

(iii) The density of the job duration $t_{e}$ in the E-stock is

$$
\varphi\left(t_{e}\right)=\frac{\delta(1+k)}{k} \int_{\delta}^{\delta(1+k)} \frac{1}{z} e^{-z t_{e}} d z
$$


Several points are worth noting. First, assumptions on the shape or the determinants of the distribution of job characteristics $w$ are not required for these results. So estimates based on the above densities are valid irrespective of the type of heterogeneity that determines the dispersion of $w$. The results are also robust with respect to the level of an institutional wage floor like a minimum wage, because $\underline{w}$ does not affect the above densities. Indeed, $F$ does not affect the densities at all. ${ }^{2}$

All densities can be expressed as a mixture of exponential distributions, with different mixing distributions that in all cases have a support $[\delta, \lambda+\delta]$. This implies that all unconditional duration densities have a decreasing hazard rate. For the E-inflow the hazard decreases from $\delta+\frac{1}{2} \lambda$ to $\delta$, for the J-inflow it decreases from $\lambda / \log (1+k)$ to $\delta$, and for the E-stock from $\delta(1+k)(\log (1+k)) / k$ to $\delta$.

On average, job spells are much longer than unemployment spells. To obtain a reasonable number of complete job spells, one must either rely on retrospective information on elapsed job spells, or one must follow a cohort during a long observation period. Retrospective information concerning a rather distant past may be unreliable due to recall errors. We can avoid these biases by censoring the job durations at a relatively short observation period. In repeated cross-section data, an alternative method is available to obtain a direct estimate of a job exit rate over some observation window, by computing the empirical hazard for this observation period. This corresponds to the calculation of retention rates (see Section 3). We use both methods.

For all three job spell distributions the hazard decreases to $\delta$ for long job spells. The difference between the hazard at duration zero and the hazard at infinity is informative on $\lambda$. If we censor the job spells after a relatively short observation period then it is difficult to recover $\delta$, and, by implication, $\lambda$. (For reasonable parameter values this is difficult even if the censoring is after 20 years.) We therefore estimate $\delta$ from external data. Specifically, we estimate an auxiliary model with data on the unemployment rate and the unemployment duration distribution to estimate $\delta$ (see Appendix A1). Given a value of $\delta$, we can estimate

\footnotetext{
${ }^{2}$ The myopic search strategy of employed workers as well as the assumptions that unemployed workers are homogeneous and flows are in equilibrium are important for these results. In the working paper version Ridder and Van den Berg (2002) we examine the robustness of the approach with respect to this.
} 
$\lambda$ from data on short job spells. ${ }^{3}$

It is useful to provide some more intuition on the identification of $\lambda$ and $k$. Consider data on $t_{u j}$ among individuals who flowed into employment at time zero. Just after time zero the value of $w$ among them is randomly distributed according to the distribution $F$. If they receive a job offer just after time zero then in $50 \%$ of all cases this is acceptable. So on average the job exit rate just after time zero equals $\delta+\frac{1}{2} \lambda$. After a while the workers who started with a low $w$ leave their job, so the composition of survivors tilts towards workers with high $w$. These have lower job exit rates, so the observable average rate decreases. By using the observed job exit rate at time zero to estimate $\lambda$, we effectively use the fraction of short job spells compared to the value of $\delta$ in order to determine the amount of search frictions in the market. A relatively large number of short job spells is taken as evidence that workers are able to move on very quickly to better jobs, so that frictions are unimportant.

We now compare the information in the data on short job durations in the different sampling designs that can be used for unconditional inference. Let $\theta_{i}$ denotes the hazard of $t_{i}$ at duration 0 . It can be shown that

$$
\begin{gathered}
\theta_{u j}-\delta=\frac{1}{2} \delta k=\delta g_{1}(k) \\
\theta_{* j}-\delta=\delta \frac{k}{\log (1+k)}-\delta=\delta g_{2}(k) \\
\theta_{e}-\delta=\delta \frac{(1+k) \log (1+k)}{k}-\delta=\delta g_{3}(k)
\end{gathered}
$$

The left hand side of these equations can be estimated by the empirical hazard rate for short job spells. By the delta method the accuracy (asymptotic variance) of the resulting estimate of $k$ is determined by the inverse of the derivatives of $g_{1}, g_{2}, g_{3}$. The derivatives satisfy $1 / 2=g_{1}^{\prime}>g_{2}^{\prime}>g_{3}^{\prime}>0$, and hence data from the E-inflow are more informative

\footnotetext{
${ }^{3}$ Simulations in our working paper version Ridder and Van den Berg (2002) show that data on longer job spells are uninformative on $\lambda$. This problem is exacerbated if $\lambda$ is itself small.
} 
than data from the J-inflow which in turn are more informative than data from the Estock. To give an example: if the observed $\theta_{e} / \delta$ equals 2.2 then the implied $k$ equals 5.5. But if the observed $\theta_{e} / \delta$ equals 2.4 then $k$ equals 7.4 . Thus, a $9 \%$ increase in the observed variable leads to a $35 \%$ increase in the value of $k$. Given the fact that published aggregate data are rounded and also contain other measurement errors, a $9 \%$ error in the value of an observable should not be considered as uncommon.

Note that the ranking of the informativeness of the data ignores differences in the sampling variation in the data. On the one hand, one may argue that the latter are all small if they concern the whole population or are based on very large samples. On the other hand one may argue that certain types of data suffer more from measurement errors, although it is hard to guess their relative magnitude.

Of course, unconditional inference uses less information than conditional inference. Conditional inference exploits the effect of the wage regressor on the job exit rate, whereas unconditional inference focuses on the duration dependence pattern of the job exit rate due to unobserved heterogeneity. The former approach is more robust from an econometric point of view, whereas the latter is more robust from a theoretical point of view.

\section{Empirical analysis for France}

\subsection{The data}

The French data we use are all extracted from the yearly French Labor Force Survey (LFS), the Enquête Emploi. The individual records of these data have been used extensively in the empirical labor economics literature (see e.g. Bontemps, Robin and Van den Berg, 2000). For the conditional (on wages) estimation of the search frictions index we also use the individual records. These data are not published. The unconditional inference uses aggregated versions of these data. We use published data from the OECD on labor market flows. Their accessibility makes inference based on them potentially attractive. In addition, we aggregate the micro data ourselves, to shed more light on the quality of the various approaches. 
The LFS is a rotating panel in which households participate for three consecutive years. They are interviewed once per year. In the first year, data are collected on the job spell with the current employer. The duration is in months if shorter than 2 years and in years if longer. In 1991, 27962 individuals were interviewed, and of these 14131 were employed; 10432 worked 35 hours or more per week; and 10210 reported a monthly gross wage. We eliminated some observations with very small and large wages (below 3000 and above 30000 French Francs). Among the remaining 9963 individuals, 9854 reported a job spell. This is the sample we use for the conditional inference as well as for the unconditional inference based on our own aggregations. Figure 1 gives the marginal distribution of elapsed job durations $t_{e}$, by year (41 means 41 years or longer). Note that there is no evidence of heaping.

Concerning the published aggregate data we use the 1995 distribution of elapsed job durations over a small number of duration intervals, as published in OECD (1997). In addition, Table 5.10 in OECD (1997) provides the separation rate from 1 year to 2 years, which is calculated as the difference between the number employed with tenure less than 1 year in 1994 and the number employed with tenure between 1 and 2 years in 1995, as a fraction of the former. This is the fraction of jobs with a duration less than a year that are dissolved within a year, or the separation rate for new jobs, or one minus the retention rate for new jobs. We denote the reported separation rate by $s_{1}$ (the index denotes the maximum elapsed job duration in the baseline year).

Table 1 presents some summary statistics of the labor markets in France and the countries we consider in Section 4. In the sequel we do not report standard errors. In cases where there are fewer parameters than observations, these standard errors depend on the details of the sample design, and these details are not available to us.

\subsection{Conditional inference results}

In Subsection 2.2 we showed that the theory predicts a linear relation between the average job spell and the earnings cdf. To check this relation we grouped wages by $5 \%$ intervals and computed the average job spell for each wage interval. The results are in Figure 2. 
We conclude that the predicted relationship holds well. A linear regression gives $R^{2}=0.93$ and $k=1.4$.

In Table 2 we report ML estimates of $k$ as a parameter of the job duration hazard, for different right-censoring values for $t_{e}$. In the hazard we substitute the empirical cdf of wages for $G$ (this gives the same equation as (2)). The estimate becomes larger if we censor the observations progressively, up to $k=4.7$ if censoring is at 2 years. This suggests that the relation between the job exit rate and the wage is different at high durations, for example because $k$ and $\delta$ are not constant and homogeneous. Bontemps, Robin and Van den Berg (2000) structurally estimate equilibrium search models for different sectors, using micro data from the LFS covering 1990-1993. The models impose that $w$ is the wage and the inference exploits wage information. Their implied estimates of $k$ are around 5 . Note that our estimator may be downward biased because the "regressor" is measured with error, as we use an estimate of $G$ instead of the population $G$.

\subsection{Unconditional inference results}

We start with the estimation using published aggregate data. Estimation of $k$ from data on $s_{1}$ as defined in Subsection 3.1 is non-trivial. First of all, the sample is not a genuine Jinflow sample but rather a sample from the stock of jobs with a duration less than one year. Secondly, the exit rate out of jobs decreases within the interval considered. To proceed, we have to derive the joint density in the E-stock of the elapsed job duration $t_{e}$ and the residual (or remaining) job duration $t_{r}$. The observation $s_{1}$ then equals

$$
s_{1}=\operatorname{Pr}\left(0<t_{r}<1 \mid 0<t_{e}<1\right)
$$

By analogy to the derivations in Subsection 2.3 we obtain

$$
s_{1}=\operatorname{Pr}\left(0<t_{r}<1 \mid 0<t_{e}<1\right)=1-\frac{\int_{\delta}^{\delta+\lambda} \frac{1}{z^{2}} e^{-z}\left(1-e^{-z}\right) d z}{\int_{\delta}^{\delta+\lambda} \frac{1}{z^{2}}\left(1-e^{-z}\right) d z}
$$

The estimated $k$ is well above 20, which is much higher than what is typically found in the literature, and certainly much higher than the conditional inference estimates mentioned in the previous subsection. The empirical distribution of individual elapsed job 
durations in the LFS reveals that France has a high fraction of jobs with a duration of less than or equal to a year (see Figure 1; spells up to two years are very frequent). This is not compatible with the shape of the unconditional job exit rate at higher durations in the current formulation of our model. Cohen, Lefranc and Saint-Paul (1997) argue that in France there are many jobs with a predetermined fixed duration mostly occupied by young workers. In particular, they argue that one can distinguish two types of job contracts: 1) with a predetermined fixed short duration, with low firing and dissolution costs, and low wages, mostly occupied by new entrants and other young workers and 2) with indeterminate long durations and high firing costs. Basically, the type-1 workers bear the burden of labor market flexibility.

One may remedy this inference problem by allowing for population heterogeneity in $\delta$ and/or $\lambda .{ }^{4}$ Another approach is to use data on separation rates $s_{T}$ for larger $T$, since these are less sensitive to the shape of the job duration density close to zero. Table 5.9 in OECD (1997) provides the separation rates from $0-<5$ years to $5-<10$ years of tenure. This gives an observation of $s_{5}$. In effect, we compare 1980-1985 with 1985-1990. The expression for $s_{5}$ is the same as for $s_{1}$, provided we replace $\delta$ and $\lambda$ by $5 \delta$ and $5 \lambda$, respectively. This gives the results on $k$ and $\lambda$ reported in Table 3 for France. These are plausible and very close to the results mentioned in the previous subsection.

Note that the conditional inference results on $k$ are not necessarily affected by the large fraction of short job spells, because those results are driven by the empirical relation between $w$ and the job exit rate, and this relation may be similar in both types of jobs.

Next, we turn to unconditional inference with the published data on numbers of elapsed job spells in a small number of duration intervals. The quasi-ML estimate of $k$ is implausibly small, and the fit to the duration data is poor. The estimates are sensitive to small changes in the value of $\delta$, but changing this value does not result in a better fit. This confirms our suspicion that these unconditional elapsed job duration data are uninformative on $k$.

Finally, we turn to unconditional inference with the micro LFS data used in the previous

\footnotetext{
${ }^{4}$ We experimented with a model in which the index of search frictions $k$ was set at a particular value and the job destruction rate $\delta$ followed a two-point mixture. This improved the fit to the observed distribution of job spells. See our working paper version Ridder and Van den Berg (2002).
} 
subsection, where we now discard the wage information. This corresponds to using the individual elapsed job spells that underlie the published data from the previous paragraph. The results are the same as in the previous paragraph. This means that these results are not due to the aggregation into duration intervals. The estimates are also sensitive to the degree in which we right-censor $t_{e}$.

We conclude that unconditional inference with the separation rate for new jobs is sensitive to institutional features of the French job contracts system. One needs to consider the separation rate for all jobs with an elapsed duration between 0 and 5 years to obtain an estimate that conforms to conditional inference estimates. Finally, unconditional inference with data on elapsed job spells is not informative on the index of search frictions.

\section{Empirical analyses for other countries}

\subsection{United Kingdom, Germany, the Netherlands}

We briefly report unconditional inference results for three other European countries. We rely again on the published data from OECD (1997). These are obtained from the yearly national Labor Force Surveys (LFS), a standardized survey that is conducted in all EU countries. The standardization facilitates comparisons of the results. The data years are the same as for France.

For the Netherlands and the UK we report the estimates based on $s_{1}$. Estimation with $s_{1}$-data gives implausible results for Germany. Like for France, the estimated $k$ is well above 20, which is much higher than for the other countries. Again, this is due to a high fraction of jobs with a duration of less than or equal to a year. And again, this can be remedied by using data on $s_{5}$ (see the results in Table 3 ).

Next, we consider the marginal frequency distribution of elapsed job spells over a small number of intervals. Like for France, the estimates of $k$ are implausible and the fit to the duration data is poor. 


\subsection{United States}

In Appendix A1 we estimate $\delta$ using a simple auxiliary model of labor market flows that ignores temporary lay-offs, voluntary quits from employment into unemployment, and new entrants and re-entrants that move from non-participation into unemployment. These are important phenomena in the U.S. labor market. Ignoring them may lead to over-estimation of $\delta$ because the inference assumes that the full unemployment inflow consists of lay-offs. The estimated $\delta$ is indeed quite large, leading to a short average duration between successive unemployment spells. This in turn may lead to under-estimation of $k$. However, as we shall see, the estimate of $k$ is still higher than for the other countries considered, so that the ranking of countries is not affected by this.

The U.S. data we use are similar to the French data, the Current Population Survey (CPS) taking the role of the French LFS. We perform conditional inference using individual records from the January 1991 supplement (see the working paper version Ridder and Van den Berg, 2002, for details). The unconditional inference uses published data from OECD (1997) based on aggregations of CPS data. The distributions of elapsed job spells are from 1996. The separation rates are calculated by numbers of employed in different duration intervals in 1995. The CPS is not harmonized with the European LFS, and this limits the comparability of the results.

The conditional inference shows that, like for France, the predicted linear relation between the average job spell and the earnings cdf holds well. Like for France, the conditional inference estimates with censoring are higher than without censoring, up to $k=6.1$ if censoring is at 2 years. In all cases, the estimates of $k$ and $\lambda$ are higher than the corresponding estimates for France. Table 3 reports the unconditional inference estimates based on $s_{1}$. These may seem large compared to the conditional inference estimates for the U.S. and to the unconditional inference estimates for the other countries. However, the estimated job offer arrival rate for employed workers is close to the U.S. job offer arrival rate for unemployed workers (see e.g. Layard, Nickell and Jackman, 1991), which is much higher than its European counterparts.

Estimation of $k$ from the marginal frequency distribution of interval-aggregated elapsed 
job spells leads to the same problems as for the other countries.

The results in this section reinforce the methodological conclusions of the previous section. Unconditional inference with the separation rate for new jobs is sensitive to institutional features. Unconditional inference with data on elapsed job spells is not informative on the index of search frictions.

The most important substantive conclusion of Sections 3 and 4 is that labor market frictions are largest in France and Germany, and smallest in the United Kingdom and the United States, with the Netherlands in between these groups of countries. This ranking is robust with respect to the method of inference. In the next section we examine the implications for wages and for policy.

\section{$5 \quad$ Policy analyses}

\subsection{Monopsony power}

We define the average monopsony power or monopsony index as follows,

$$
\mu=\frac{\mathrm{E}(p-w)}{\mathrm{E}(p)}
$$

In this equation, $p$ is the revenue product or match value (or simply productivity) of a single worker. We take expectations over individuals in the labor force instead of firms, so we examine monopsony power from the perspective of the worker. In this section we restrict attention to the case where the wage is the only job characteristic of concern to workers. To quantify $\mu$, it matters how wages are determined. This is because $\mathrm{E}(p)$ is unobserved, and we can only estimate it by using observations of $w$ and applying the inverse of the mapping between $p$ and $w$ that follows from the wage determination process.

We postulate that the wage determination process is such that at the aggregate level the following relation holds,

$$
\mathrm{E}(w)=\frac{k}{1+k} \mathrm{E}(p)+\frac{1}{1+k} \mathrm{E}(\underline{w}(p))
$$


where the notation $\underline{w}(p)$ for the lowest wage $\max \left\{r, w_{\min }\right\}$ highlights that it may be a function of $p$ by way of the reservation wage $r$ of the unemployed. Equation (6) can be rationalized by the equilibrium search model of Van den Berg and Ridder (1998). In this model, the total labor market consists of separate segments within which each worker-firm match has the same productivity $p$. This productivity may be dispersed across segments, but $k$ is the same across segments. Only segments with $p>\max \left\{b, w_{\min }\right\}$ are profitable, where $b$ is the value of leisure. This can be shown to imply that $p>\underline{w}(p)$ for each profitable $p$.

Substitution of (6) in (5) gives

$$
\mu=\frac{1}{1+k} \frac{\mathrm{E}(p)-\mathrm{E}(\underline{w}(p))}{\mathrm{E}(p)}
$$

Alternatively, $\mu$ can be expressed in terms of $k, \mathrm{E}(w)$ and $\mathrm{E}(\underline{w}(p))$,

$$
\mu=\frac{\mathrm{E}(w)-\mathrm{E}(\underline{w}(p))}{(1+k) \mathrm{E}(w)-\mathrm{E}(\underline{w}(p))}
$$

$\mathrm{E}(w)$ is observed, and $k$ has been estimated, so it remains to quantify $\mathrm{E}(\underline{w}(p))$. If $r<w_{\min }$ for all $p$ then $\mathrm{E}(\underline{w}(p))=w_{\text {min }}$, which is observed. Otherwise we need a model to express $\underline{w}(p)$ and the distribution of $p$ across segments in terms of observables or estimable quantities. We use the full Van den Berg and Ridder (1998) model for this purpose as well as to determine whether $r<w_{\text {min }}$ for all $p$. Appendix A2 gives details.

\subsection{Effects of policy changes}

From equation (7), the only feature of the wage distribution that affects the degree of monopsony is the average of the lowest wage over all workers. Consider now the role of $w_{\text {min }}$. If it exceeds $r$ for a certain segment with a certain $p$ then a further increase in it shifts the whole wage offer and earnings distributions upwards. That is, it redistributes the rents of the match by lowering the profits of all employers and raising the income of all workers. In effect, it decreases the monopsony power of firms. However, if the minimum wage exceeds the productivity $p$, then firms will close, and all workers become permanently (structurally) unemployed. (The same holds if $b>p$.) 
In the limiting case where $w_{\text {min }}$ equals $p$ for each segment, the value of $\mu$ attains its minimum value 0. Similarly, if $k$ is infinite then $\mathrm{E}(w)=E(p)$ and again $\mu=0$. If, on the other hand, $k=0$ and $\underline{w}(p)=0$ for every $p$ then $\mu$ attains its maximum value (which is 1). This suggests that it is interesting to contrast wage floor policies to policies that affect the amount of frictions.

The estimates and observations needed to quantify $\mu$ (see Subsection 5.1 and Appendix A2) can be used to compute a number of counterfactual monopsony indices. In particular, we consider (i) the effect of reducing unemployment benefits, while leaving the minimum wage unaffected, (ii) the effect of reducing the minimum wage, while leaving the unemployment benefits unaffected, (iii) the effect of eliminating both the minimum wage and unemployment benefits, and (iv) the effect of making search on the job impossible. ${ }^{5}$

To quantify $\mu$ we require wage data. We use categorized wage data from the early 1990s on before-tax monthly wages of full-time employees who worked during the whole year (see our working paper version Ridder and Van den Berg, 2002, for details). The minimum wage and unemployment benefits levels are taken from CPB (1995). We use the estimates of $k$ in Table 3. Table 4 lists the estimates of the monopsony indices.

For all countries the average monopsony power is smaller than $5 \%$. For this reason it is more informative to consider counterfactuals that increase the monopsony index than counterfactuals that decrease this index. Elimination of unemployment benefits and of the minimum wage barely increases the monopsony indices. The index for the counterfactual $k=0$ shows convincingly that the main protection of workers against the monopsony power of firms is provided by the ability to move to high-wage jobs. ${ }^{6}$

\footnotetext{
${ }^{5}$ Note that the actual productivity distribution is truncated from below at the minimum wage. All counterfactuals that involve a reduction of the minimum wage below its current level must be interpreted with care. A reduction of the minimum wage lowers the truncation point of the productivity distribution, and the effect of this extension on the monopsony index depends on the untruncated density at the new minimum wage. In general, the average productivity will decrease with a decrease in the minimum wage. Because we do not want to rely on the estimated productivity density below the truncation point, the counterfactuals assume that the average productivity does not change with the minimum wage.

${ }^{6}$ Note that the estimate of $k$ is almost perfectly negatively related to the employment protection ranking in Table 1.
} 
Although our analysis is too simple for a careful welfare analysis of the minimum wage, it is clear that the argument that the minimum wage is needed to protect workers against monopsonistic employers is not convincing. Of course, our analysis does not allow for individual variation in the rate of job-to-job transitions, but on average these transitions seem to protect the workers sufficiently well. Moreover, wage floors create structural unemployment among less productive workers. If one is interested in worker protection then it is more useful to focus on policy measures that stimulate on-the-job search and job-to-job transitions. The former can be implemented by subsidizing agencies that arrange contacts between workers and firms, or by making the costs of job search tax-deductible. Job-to-job transitions can be stimulated by subsidizing the costs of moving or by stimulating the use of insurance and pension schemes that are not restricted to single firms or sectors, so that workers do not have to give up certain rights when they move between firms or sectors.

Note that higher reservation wages of unemployed workers may also reduce the monopsony index. According to equilibrium search models, this can be established by a high job offer arrival rate for unemployed workers. In that case the reservation wage of highproductivity workers exceeds $w_{\min }$.

At this stage it may be useful to examine which data features drive the policy results, and how the data have to look like to obtain different conclusions. The main equations that link the parameters of interest to the data are (i) equation (4) or equation (2) for the relation between the index of search frictions $k$ and the data on short job durations, and (ii) equation (8) for the relation between the monopsony index $\mu$ and the wage data, given $k$. The policy results follow directly from (ii). It turns out that the policy results are not very sensitive to the value of $k$. For reasonable $k$ the monopsony indices are small. If a newly employed worker obtains on average at least three job opportunities before being laid off then the monopsony index is always smaller than 0.25 . The estimates of $k$ are in a fairly wide range, depending on the country and the method of inference. In the case of unconditional inference one would need to observe a smaller fraction of short term jobs than is actually observed, in order to obtain an estimate of $k$ that generates a large $\mu$ and a larger role for wage floor policies. In the case of conditional inference one would need 
to observe a weaker dependence of the job exit rate on the wage quantile than actually observed, in order to reach such conclusions.

\section{Conclusion}

We developed and used two approaches to estimate the index of search frictions. The conditional inference approach is more robust from an econometric point of view, whereas the unconditional inference approach is more robust from an economic-theoretical point of view. It turns out that unconditional inference with data on elapsed job spells is not informative on the index of search frictions. Unconditional inference with the separation rate for new jobs is sensitive to institutional features. Provided these features are taken into account, reasonable estimates are obtained.

The methods of inference have deliberately been designed to be easily implementable and to require only easily available data. In such a case it comes as no surprise that the data sometimes suggest that there is more heterogeneity than the method of inference can handle. Nevertheless, the ranking of countries with respect to the index of search frictions is robust with respect to the method of inference. Moreover, the results on the amount of monopsony power and the policy effects are unambiguous. For all countries we find a small amount of monopsony power. In the absence of job mobility of employed workers, the monopsony power would be much higher. In the absence of a wage floor, the monopsony power would only be marginally higher. We conclude that in all countries, job mobility provides much more protection against exploitation of workers than a wage floor.

Some topics for future research emerge. First, it seems useful to investigate further how robust unconditional inference with data on separation rates is from an econometric point of view. Secondly, methods may be designed that allow for more individual heterogeneity while still being easy to implement. 
Table 1: Some characteristics of the labor markets in the five countries

\begin{tabular}{|c|c|c|c|c|c|}
\hline & NL & $\mathrm{D}$ & $\mathrm{F}$ & UK & USA \\
\hline $\begin{array}{l}\text { Average standardized unem- } \\
\text { ployment rate (1989-1993) }\end{array}$ & 6.9 & 5.1 & 9.9 & 8.7 & 6.2 \\
\hline $\begin{array}{l}\text { Monthly flow out of unempl. } \\
\text { (\% of unempl.; av. over } 1985 \\
\text { and 1993) }\end{array}$ & 6.6 & 7.6 & 3.6 & 7.7 & 39.4 \\
\hline $\begin{array}{l}\text { Monthly flow into unempl. (\% } \\
\text { of empl.; av. over } 1985 \text { and } \\
1993)\end{array}$ & 0.26 & 0.41 & 0.33 & 0.59 & 2.26 \\
\hline $\begin{array}{l}\text { Monthly flow of hires (\% of } \\
\text { empl.; av. various years) }\end{array}$ & 0.99 & 2.63 & 2.42 & - & 5.38 \\
\hline Average wedge (\%) & 44 & 41 & 38 & 29 & 33 \\
\hline $\begin{array}{l}\text { Minimum wage (max. of } \\
\text { statutory and collective; } \\
\text { Euros per year) }\end{array}$ & 14010 & 9940 & 10790 & 7000 & 7540 \\
\hline $\begin{array}{l}\text { Min. wage as frac. wage av. } \\
\text { production worker }\end{array}$ & 0.57 & 0.38 & 0.63 & 0.39 & 0.35 \\
\hline $\begin{array}{l}\text { Average minimum unempl. } \\
\text { benefit (Euros per year) }\end{array}$ & 11780 & 9480 & 7540 & 5750 & 5770 \\
\hline $\begin{array}{l}\text { Employment protection rank- } \\
\text { ing }\end{array}$ & 3 & 5 & 4 & 2 & 1 \\
\hline
\end{tabular}

Germany is West Germany only; sources: OECD Employment Outlooks and CPB (1995).

Table 2: Conditional inference estimates of index of search frictions in France; job durations censored at year $\mathrm{C}$

\begin{tabular}{cccc}
\hline Uncensored & $C=20$ & $C=5$ & $C=2$ \\
\hline 1.3 & 2.6 & 4.2 & 4.7 \\
& & & \\
\hline
\end{tabular}


Table 3: Unconditional inference estimates of the index of search frictions

\begin{tabular}{lrr}
\hline & $\lambda$ (per month) & $k$ \\
\hline Netherlands & 0.072 & 9.1 \\
Germany & & \\
France & 0.028 & 6.5 \\
& & \\
United Kingdom & 0.038 & 5.0 \\
& & \\
United States & 0.13 & 13 \\
& & \\
\hline
\end{tabular}

Table 4: (Counterfactual) monopsony power indices

\begin{tabular}{lccccc}
\hline & Germany & Netherlands & France & United Kingdom & United States \\
\hline$\mu$ & 0.0068 & 0.029 & 0.025 & 0.046 & 0.036 \\
$\mu_{b=0}$ & .010 & 0.034 & 0.037 & 0.046 & 0.036 \\
$\mu_{w_{\min }=0}$ & 0.0070 & 0.031 & 0.027 & 0.047 & 0.040 \\
$\mu_{w_{\min }=b=0}$ & 0.011 & 0.060 & 0.046 & 0.063 & 0.053 \\
$\mu_{k=0}$ & 0.62 & 0.44 & 0.52 & 0.69 & 0.68 \\
& & & & & \\
\end{tabular}


Figure 1: Frequency distribution job durations; France, 1991

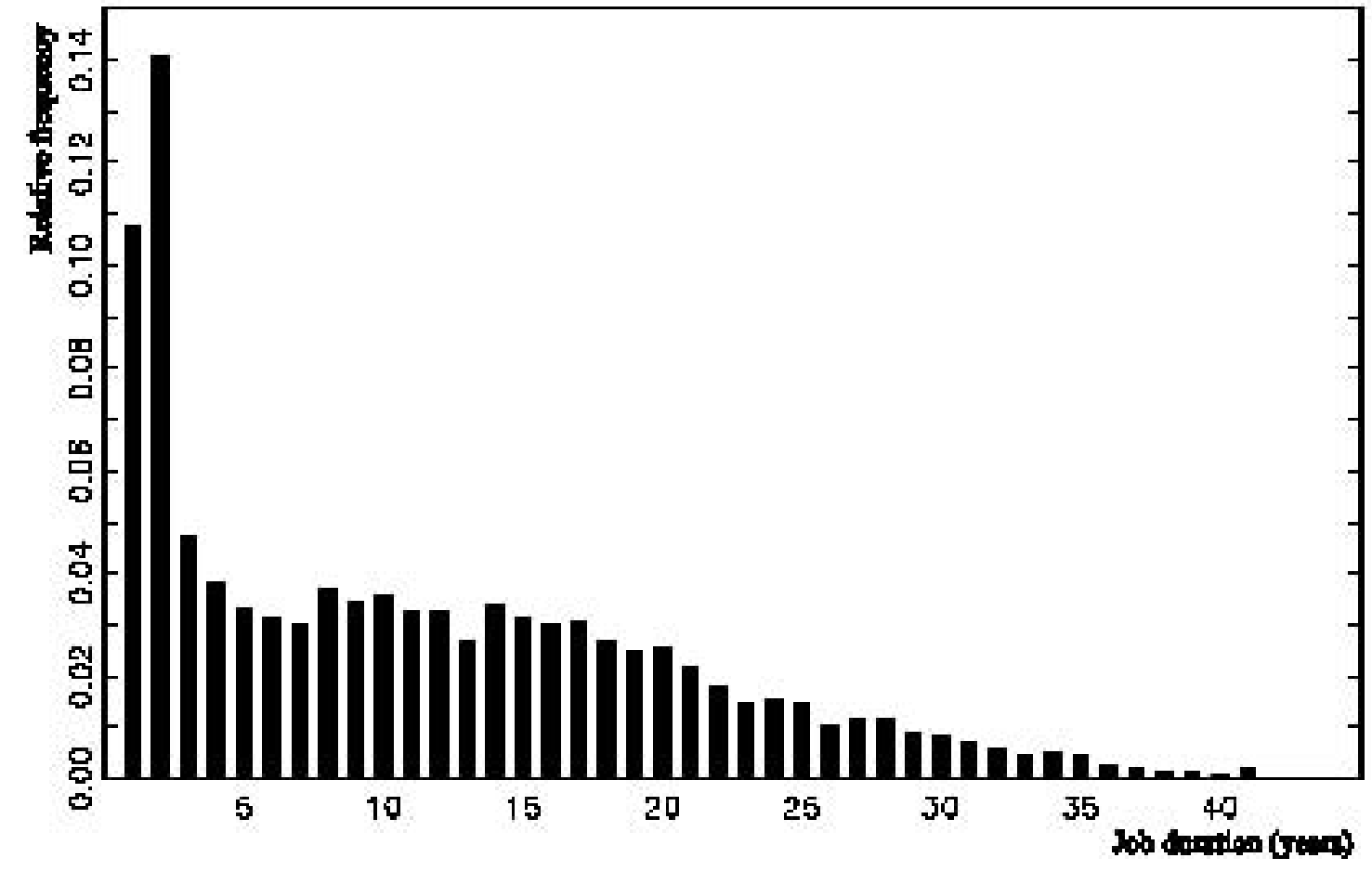

Figure 2: Average job duration by 5\% wage intervals; France, 1991

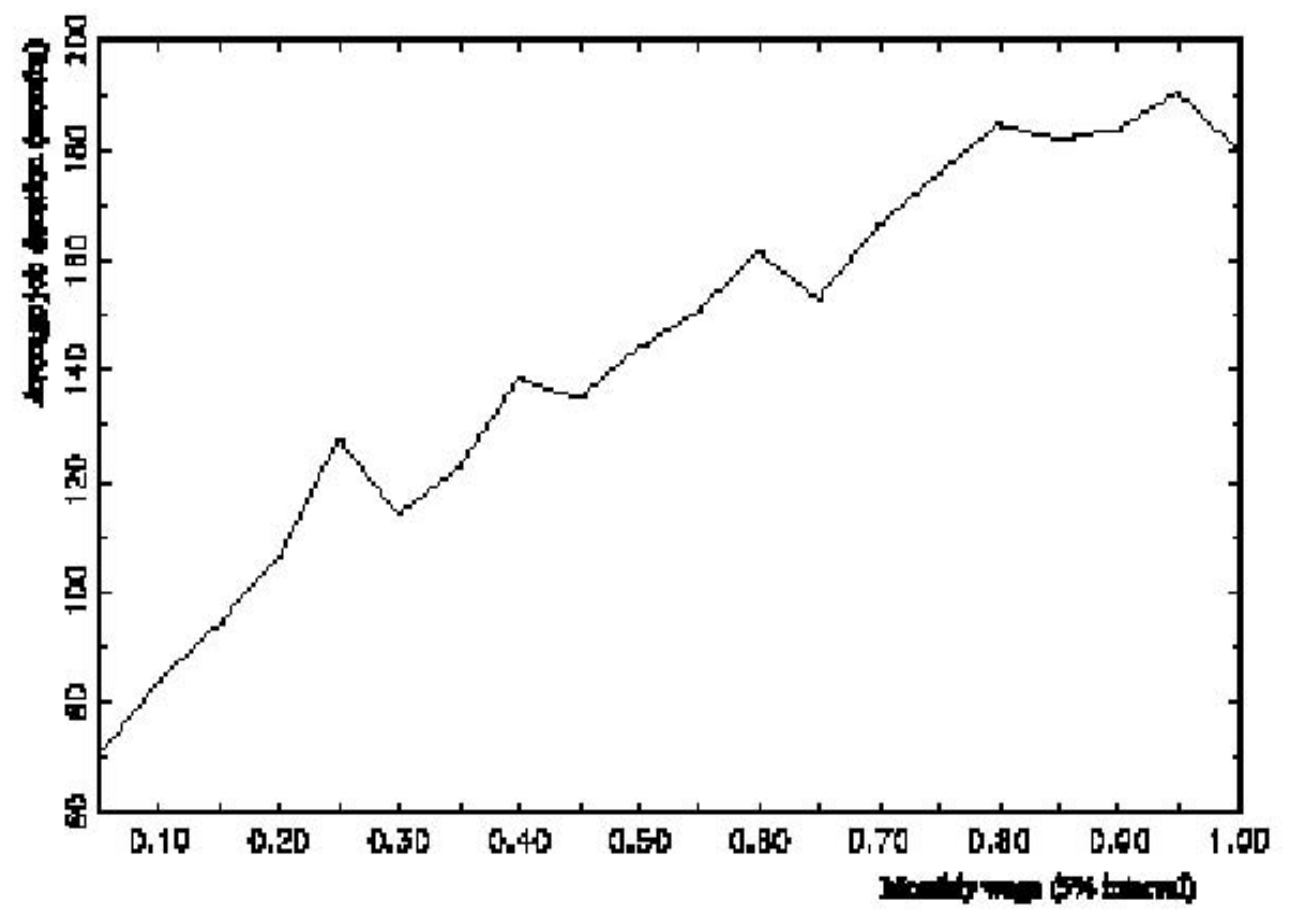




\section{References}

Bontemps, C., J.M. Robin, and G.J. van den Berg (2000), "Equilibrium search with continuous productivity dispersion: theory and non-parametric estimation", International Economic Review, 41, 305-358.

Burdett, K. and D.T. Mortensen (1998), "Wage differentials, employer size, and unemployment", International Economic Review, 39, 257-273.

Cohen, D., A. Lefranc, and G. Saint-Paul (1997), "French unemployment: a transatlantic perspective", Economic Policy, 25, 267-285.

CPB (1995), "Replacement rates", Working paper, Central Planning Bureau, The Hague.

Flinn, C.J. (2002), "Labor market structure and inequality: a comparison of Italy and the U.S.", Review of Economic Studies, 69, 611-645.

Gronberg, T.J. and W.R. Reed (1994), "Estimating workers' marginal willingness to pay for job attributes using duration data", Journal of Human Resources, 29, 911-931.

Hwang, H.S., D.T. Mortensen and W.R. Reed (1998), "Hedonic wages and labor market search", Journal of Labor Economics, 16, 815-847.

Layard, R., S. Nickell, and R. Jackman (1991), Unemployment; Macroeconomic Performance and the Labour Market, Oxford University Press, Oxford.

Mortensen, D.T. (1986), "Job search and labor market analysis", in O. Ashenfelter and R. Layard, editors, Handbook of Labor Economics, North-Holland, Amsterdam.

Mortensen, D.T. and C.A. Pissarides (1999), "New developments in models of search in the labor market", in O. Ashenfelter and D. Card, editors, Handbook of Labor Economics, Volume III, North-Holland, Amsterdam.

OECD (1997), Employment Outlook 1997, OECD, Paris.

Ridder, G. (1984), "The distribution of single-spell duration data", in: G.R. Neumann and N. Westergård-Nielsen, editors, Studies in labor market analysis, Springer Verlag, Berlin. 
Ridder, G. and G.J. van den Berg (1997), "Empirical equilibrium search models", in D.M. Kreps and K.F. Wallis, editors, Advances in Economics and Econometrics: Theory and Applications, Cambridge University Press, Cambridge.

Ridder, G. and G.J. van den Berg (2002), "A cross-country comparison of labor market frictions", Working paper, Free University Amsterdam, Amsterdam.

Van den Berg, G.J. (1999), "Empirical inference with equilibrium search models of the labor market", Economic Journal, 109, F283-F306.

Van den Berg, G.J. and G. Ridder (1998), "An empirical equilibrium search model of the labor market", Econometrica, 66, 1183-1221.

Van den Berg, G.J. and A. van Vuuren (2001), "The effect of search frictions on wages", Working paper, Free University and Tinbergen Institute, Amsterdam. 


\section{Appendix}

\section{A1. Estimation of the transition rate from employment to unemployment}

We postulate a simple steady-state model of unemployment that allows the stock of unemployed to consist of two groups: the structurally unemployed with zero exit rate, and the frictionally unemployed with exit rate $\lambda_{0}$. The latter sub-stock has a changing composition, whereas the former does not. The structural unemployment rate as a fraction of the labor force is denoted by $q$. Consequently, the unemployment rate $U$ equals $q+(1-q) \delta /\left(\delta+\lambda_{0}\right)$.

We aim to estimate $\delta$ using aggregate unemployment data. It is clear that data on $U$ by themselves do not identify $\delta$. We also use data on the frequency distribution of elapsed unemployment durations in the stock of unemployed. The latter identify $\lambda_{0}$ and $q$, so that $\delta$ is subsequently identified from $U$.

The amount of structural unemployment as a fraction of total unemployment can then be expressed as $q / U$, which will be denoted by $\pi$. (Consequently, the structural and frictional unemployment rates can be expressed as $\pi U$ and $(1-\pi) U$, respectively.) Now consider a large sample from the stock of unemployed persons. A fraction $\pi$ has a zero exit rate and infinite unemployment durations. A fraction $1-\pi$ has an exit rate equal to $\lambda_{0}$. An inflow sample of these frictionally unemployed has an unemployment duration distribution that is exponential with parameter $\lambda_{0}$. It is well known that the corresponding distribution of elapsed durations in the stock has the same distribution. We do not observe to what type an unemployed individual belongs. Consequently, the observed distribution $\Psi(t)$ of elapsed durations $t$ in the stock is a mixture of a degenerate distribution with a single mass point at infinity and an exponential distribution with parameter $\lambda_{0}$. The survival function equals

$$
\bar{\Psi}(t) \equiv 1-\Psi(t)=\pi+(1-\pi) e^{-\lambda_{0} t}
$$

This is a discrete mixture of exponentials with two mass points, one of which is fixed at zero. Aggregate data provide observations on the fraction of unemployed in a finite number of duration intervals $\left[t_{i}, t_{i+1}\right)$. The corresponding probabilities equal $\Psi\left(t_{i+1}\right)-\Psi\left(t_{i}\right)$. Thus, the parameters $\lambda_{0}$ and $\pi$ (and therefore $q$ ) can be readily estimated.

The distributions of elapsed unemployment spells and the unemployment rate were obtained from OECD publications. These are in turn based on data from the Labor Force Survey (NL, D, F, UK) and the Current Population Survey (US). For the US the unemployment rate is standardized (see the working paper version Ridder and Van den Berg, 2002, for details).

The parameters $\lambda_{0}$ and $\pi$ are estimated by quasi ML. The estimates obtained by maximizing the grouped duration likelihood are quasi MLE because neither the LFS, nor the CPS is a simple random sample. Although the estimators are consistent for a stratified sample, provided that the stratification variables are exogenous, the standard errors depend on the details of the sample design. Note that the 
Table 5: Offer arrival rate (per month) $\left(\lambda_{0}\right)$ and average unemployment duration (months) of frictionally unemployed, 1990-91

\begin{tabular}{|c|cc|cc|cc|cc|cc|}
\hline \multirow{2}{*}{ Year } & \multicolumn{2}{|c|}{ NL } & \multicolumn{2}{c|}{ D } & \multicolumn{2}{c|}{ F } & \multicolumn{2}{c|}{ UK } & \multicolumn{2}{c|}{ US } \\
\hline 90 & $\lambda_{0}$ & av. dur. & $\lambda_{0}$ & av. dur. & $\lambda_{0}$ & av. dur. & $\lambda_{0}$ & av. dur. & $\lambda_{0}$ & av. dur. \\
91 & 0.120 & 8.4 & 0.0975 & 10.3 & 0.0933 & 10.7 & 0.156 & 6.4 & 0.563 & 1.8 \\
\hline
\end{tabular}

Table 6: Fraction of unemployment that is structural $(\pi)$ and job destruction rate $(\delta)$ per month, 1990-91

\begin{tabular}{|c|cc|cc|cc|cc|ccc|}
\hline & \multicolumn{2}{|c|}{$\mathrm{NL}$} & \multicolumn{2}{c|}{$\mathrm{D}$} & \multicolumn{2}{c|}{$\mathrm{F}$} & \multicolumn{2}{c|}{ UK } & \multicolumn{2}{c|}{ US } \\
Year & $\pi$ & $\delta$ & $\pi$ & $\delta$ & $\pi$ & $\delta$ & $\pi$ & $\delta$ & $\pi$ & $\delta$ \\
\hline 90 & 0.28 & 0.00733 & 0.22 & 0.00391 & 0.18 & 0.00798 & 0.22 & 0.00912 & 0.073 & .0304 \\
91 & 0.26 & 0.00750 & 0.21 & 0.00339 & 0.16 & 0.00792 & 0.15 & 0.0122 & 0.080 & .0309 \\
\hline
\end{tabular}

grouped MLE is less sensitive to rounding errors in the unemployment durations. We only present the estimation results for the years 1990 and 1991.

A2. The monopsony power if the reservation wage exceeds the mandatory minimum wage in certain labor market segments

The Van den Berg and Ridder (1998) model expresses $r$ (and, therefore, $\underline{w}(p)$ ) for each segment in terms of $\lambda, p, b, w_{\min }, \delta$ and the job offer arrival rate $\lambda_{0}$ for the unemployed. There holds that $r<>b$ iff $\lambda_{0}<>\lambda$. If $\lambda_{0}>\lambda$ then $\underline{w}(p)$ for the high productivity workers is equal to their reservation wage that is larger than the minimum wage. The lowest wage for the low productivity workers is then the minimum wage. Otherwise, the reservation wage of the unemployed is always smaller than the minimum wage.

Consider the case $\lambda_{0}>\lambda$. We fit a lognormal distribution to the grouped wage distribution. Next, we compute the mean and variance of this wage distribution. Finally, we equate the estimated mean and variance of $w$ to the corresponding model expressions. The result is a nonlinear system that involves the first two moments of truncated distributions of $p$ across workers. If we choose a lognormal distribution for $p$, we obtain a nonlinear system in the parameters of this distribution, and this system can be solved numerically, plugging in the estimates of $\lambda$ (see Sections 3 and 4), and $\delta$ and $\lambda_{0}$ (see Appendix A1) and the observations of $b$ and $w_{\text {min }}$. 


\section{IZA Discussion Papers}

\begin{tabular}{|c|c|c|c|c|}
\hline No. & Author(s) & Title & Area & Date \\
\hline 800 & $\begin{array}{l}\text { T. Beissinger } \\
\text { C. Knoppik }\end{array}$ & $\begin{array}{l}\text { Sind Nominallöhne starr? Neuere Evidenz und } \\
\text { wirtschaftspolitische Implikationen }\end{array}$ & 7 & $06 / 03$ \\
\hline 801 & A. Launov & $\begin{array}{l}\text { A Study of the Austrian Labor Market Dynamics } \\
\text { Using a Model of Search Equilibrium }\end{array}$ & 2 & $06 / 03$ \\
\hline 802 & $\begin{array}{l}\text { H. Antecol } \\
\text { P. Kuhn } \\
\text { S. J. Trejo }\end{array}$ & $\begin{array}{l}\text { Assimilation via Prices or Quantities? Labor } \\
\text { Market Institutions and Immigrant Earnings } \\
\text { Growth in Australia, Canada, and the United } \\
\text { States }\end{array}$ & 1 & $06 / 03$ \\
\hline 803 & R. Lalive & Social Interactions in Unemployment & 3 & $06 / 03$ \\
\hline 804 & J. H. Abbring & Dynamic Econometric Program Evaluation & 6 & $06 / 03$ \\
\hline 805 & $\begin{array}{l}\text { G. J. van den Berg } \\
\text { A. van Vuuren }\end{array}$ & The Effect of Search Frictions on Wages & 6 & $06 / 03$ \\
\hline 806 & G. J. van den Berg & $\begin{array}{l}\text { Multiple Equilibria and Minimum Wages in Labor } \\
\text { Markets with Informational Frictions and } \\
\text { Heterogeneous Production Technologies }\end{array}$ & 6 & $06 / 03$ \\
\hline 807 & $\begin{array}{l}\text { P. Frijters } \\
\text { M. A. Shields } \\
\text { N. Theodoropoulos } \\
\text { S. Wheatley Price }\end{array}$ & $\begin{array}{l}\text { Testing for Employee Discrimination Using } \\
\text { Matched Employer-Employee Data: } \\
\text { Theory and Evidence }\end{array}$ & 5 & $06 / 03$ \\
\hline 808 & $\begin{array}{l}\text { F. Docquier } \\
\text { H. Rapoport }\end{array}$ & $\begin{array}{l}\text { Remittances and Inequality: A Dynamic } \\
\text { Migration Model }\end{array}$ & 1 & $06 / 03$ \\
\hline 809 & $\begin{array}{l}\text { S. Commander } \\
\text { M. Kangasniemi } \\
\text { L. A. Winters }\end{array}$ & The Brain Drain: Curse or Boon? & 1 & $06 / 03$ \\
\hline 810 & $\begin{array}{l}\text { J. H. Abbring } \\
\text { G. J. van den Berg }\end{array}$ & $\begin{array}{l}\text { A Simple Procedure for the Evaluation of } \\
\text { Treatment Effects on Duration Variables }\end{array}$ & 6 & $06 / 03$ \\
\hline 811 & $\begin{array}{l}\text { M. Corak } \\
\text { W.-H. Chen }\end{array}$ & $\begin{array}{l}\text { Firms, Industries, and Unemployment Insurance: } \\
\text { An Analysis Using Employer-Employee Data }\end{array}$ & 1 & $06 / 03$ \\
\hline 812 & $\begin{array}{l}\text { J. T. Addison } \\
\text { T. Schank } \\
\text { C. Schnabel } \\
\text { J. Wagner }\end{array}$ & $\begin{array}{l}\text { German Works Councils in the Production } \\
\text { Process }\end{array}$ & 3 & $06 / 03$ \\
\hline 813 & E. P. Lazear & $\begin{array}{l}\text { Firm-Specific Human Capital: A Skill-Weights } \\
\text { Approach }\end{array}$ & 5 & $06 / 03$ \\
\hline 814 & $\begin{array}{l}\text { G. Ridder } \\
\text { G. J. van den Berg }\end{array}$ & $\begin{array}{l}\text { Measuring Labor Market Frictions: A Cross- } \\
\text { Country Comparison }\end{array}$ & 6 & $7 / 03$ \\
\hline
\end{tabular}

An updated list of IZA Discussion Papers is available on the center's homepage www.iza.org. 